\title{
Creep Behavior and Crack Interference Effective of P91-Type Steel Under High Temperature
}

\author{
Ping Tang \\ Zhejiang Provincial Special Equipment Inspection and \\ Research Institute \\ Hangzhou, 310020, P. R. China \\ tangpingjob@163.com \\ Zhangwei Ling \\ Zhejiang Provincial Special Equipment Inspection and \\ Research Institute \\ Hangzhou, 310020, P. R. China \\ lingzhangwei@163.com
}

\author{
Nanhui Jin \\ Zhejiang Provincial Special Equipment Inspection and \\ Research Institute \\ Hangzhou, 310020, P. R. China \\ 1940977087@qq.com \\ Min Wang \\ Zhejiang Provincial Special Equipment Inspection and \\ Research Institute \\ Hangzhou, 310020, P. R. China \\ wangmin@nbu.edu.cn
}

\begin{abstract}
P91-type steel is widely used for the hightemperature pipe work components in advanced power plants. It exhibits a considerable high-temperature creep strength, a high corrosion-cracking resistance, a low oxidation rate, and good weldability. According to the relevant standard, plane defects were usually regularization characterized. But, how regularization characterize the plane defects under high temperature were not directly given. Thus, in the paper, elliptical crack was taken as an example. Based on the new combined constitutive mode, the creep crack stress distribution of p91-type steel was studied, and the law of crack interference effective was given. The result shows that the interference effects are still evident, when the distance interference is 2 times the critical interference spacing. Thus, coefficient compensation must be given in safety assessment at high temperatures. The compensation range is 2 times the critical interference spacing. The results provide theoretical support to the formulation of safety assessment standard under high temperature.
\end{abstract}

Keywords- creep; crack; P91-type steel; interference; high temperature

\section{INTRODUCTION}

During the past years, considerable efforts have been made to obtain the fundamental understanding of creep damage behavior of solids at high temperature. Continuum damage models have been widely used to simulate the material degradation due to microstructural evolution[1-3]. The creep behavior of the P91-type steel has been studied by many researchers during the past years[4-6]. Numerous continuum damage mechanics models coupling with plasticity, viscoplasticity, creep, and fatigue have been developed. Based on this models, the crack creep behavior under high temperature also has been studied by many researchers. T.H. Hyde carried out the creep crack growth tests on compact tension (CT) specimens machined from a P91weldment. The results obtained showed that, the creep crack growth rates for parent material specimens are about ten times lower than those for the cross-weld specimens and that the scatter in the data is relatively high[7,8]. S. Maleki provided a review and reanalysis of published information using properties quoted in codes of practice and from recent research data regarding the creep crack growth of P91 steel, and uses existing models to predict its behavior[9]. G.Z. Wang quantitatively investigated the creep crack-tip constraint induced by loading configuration of specimens using the finite element method[10].

In many high temperature applications the accumulation of creep strain during the primary stage cannot be ignored since most of the allowable design strain occurs in this stage. At the same time, the creep behavior of the P91-type steel has been studied by several researchers during the past years. Since it is well known that the creep behavior of P91-type steel cannot be satisfactorily described by a simple, Arrhenius-type, power-law constitutive model. Based on the Norton-Bailey creep and Kachanov-Rabotnov creep damage, in the literature [11] a new combined constitutive model has been developed, in which the creep and damage function are both considered as nonlinear variables. The results indicated that this combined damage model is applicable to describe the full damage evolution for P91-type steel. Based on this new combined constitutive mode, in the paper, creep behavior and crack interference effective of p91-type steel was studied.

According to the relevant standard, such as safety assessment for in-service pressure vessels containing defects, plane defects are usually regularization characterized. And the crack defect characterized to ellipse, circle, semi-elliptical or rectangle. But, how regularization characterize the plane defects under high temperature were not directly given. Thus, in the paper, elliptical crack was taken as an example. Based on the new combined constitutive mode, the creep crack stress distribution of p91-type steel was studied, and the law of crack interference effective were given. 


\section{CONSTITUTIVE MODELING}

A general form of the constitutive and damage evolution equations related to the creep deformation at small strain and creep damage growth in an initially isotropic material. The full creep model can be written as follows:

$$
\varepsilon_{c}=\varepsilon_{c}^{h}+\varepsilon_{c}^{d}
$$

Here, $\varepsilon_{c}^{h}$ is the hardening creep strain; $\varepsilon_{c}^{d}$ is the damage creep strain.

According to the literature [11], based on NortonBailey creep law and creep damage model, a new constitutive combined model has been developed, in which the creep and damage function are both considered as nonlinear variables, and the stress can be taken as effective stress. The analytical results are in good agreement with the benchmark experiment data. This proposed method can be applied to effectively predict the full creep damage stages and the failure of P91-type steel in future. The combined creep damage model is given as:

$$
\varepsilon_{c}=A_{1} \sigma_{e}^{n} t^{m} e^{-\frac{Q}{R T}}+A_{2} \sigma_{e}^{\omega}\left(1-\left(1-\frac{t}{t_{R}}\right)^{\theta}\right)
$$

And the rate equation of the combined creep damage for the numerical simulation is given as:

$$
\dot{\varepsilon}_{c}=A_{1} \sigma_{e}^{n} m t^{m-1} e^{-\frac{Q}{R T}}+A_{2} \sigma_{e}^{\omega} \theta\left(1-\frac{t}{t_{R}}\right)^{\theta-1}
$$

\section{CRACK CREEP BEHAVIOR}

\section{A. Numerical Simulated Model}

In the paper, elliptical crack was taken as an example. The numerical simulated model and elliptical crack was shown in Fig .1. The mesh in the crack were refinement, and the mesh dependencies were considered by refining several types of elements. A convergence was considered when the maximum of the summation of the residual of all the elements was less than $0.1 \%$. The boundary conditions is shown in Fig .1. The a-axis direction of the elliptical crack along the principal stress, and b-axis in the vertical direction.

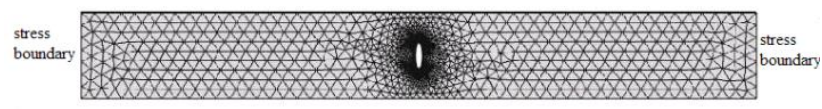

Figure 1. The numerical simulated model.

\section{B. Crack Creep Behavior Analysis}

Taken elliptical crack with $a: b=1: 4$ for example. Fig .2 is creep stress distribution of the numerical simulated model. As shown in Fig .3, the stress concentration is very obvious in the tip of crack long axis. In order to descript the creep stress distribution with the extension of time, eight key points were selected, as shown in Fig .2. And the creep stress distribution with the extension of time was shown in Fig .4. As shown in Fig .4, the maximum creep stress values is always in the tip of crack long axis(P4,P5). And in the early creep stage, the creep stress is very large, with the extension of the creep time, the creep stress gradually decreases to a steady value. But in the late stage, an obvious creep stress fluctuation was appeared, that is because of late creep stress relaxation. The variation of creep stress in the tip of crack short axis $(\mathrm{P} 3, \mathrm{P} 6)$ is similar to the long axis, but the creep stress values is smaller, and creep stress fluctuation is not obvious. As for P1,P2, P7,P8, the creep stress fluctuation are disappear. Thus the stress concentration is very obvious in the tip of crack. The maximum creep stress values is always in the tip of crack long axis, which is 2.7 times the average stress values. Fig .5 is the creep strain distribution with the extension of time. As shown in Fig .5, creep strain concentrated in the end of the long axis(P4,P5).

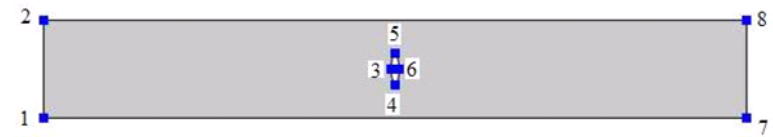

Figure 2. The position of eight key points

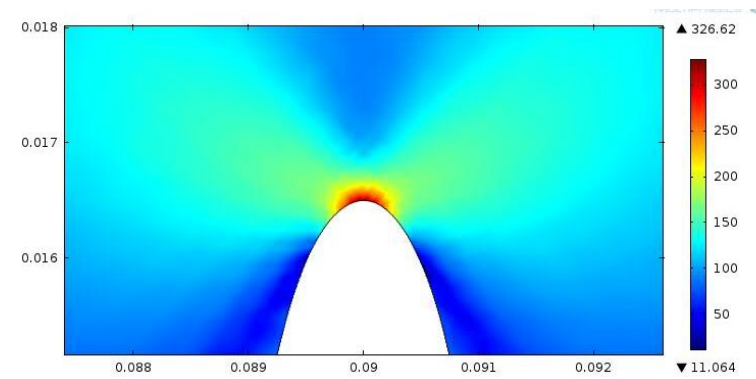

Figure 3. Creep stress distribution of the numerical simulated model.

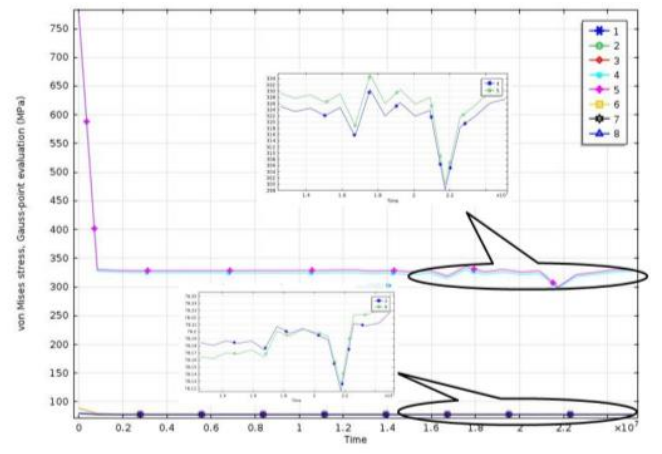

Figure 4. The creep stress distribution with the extension of time.

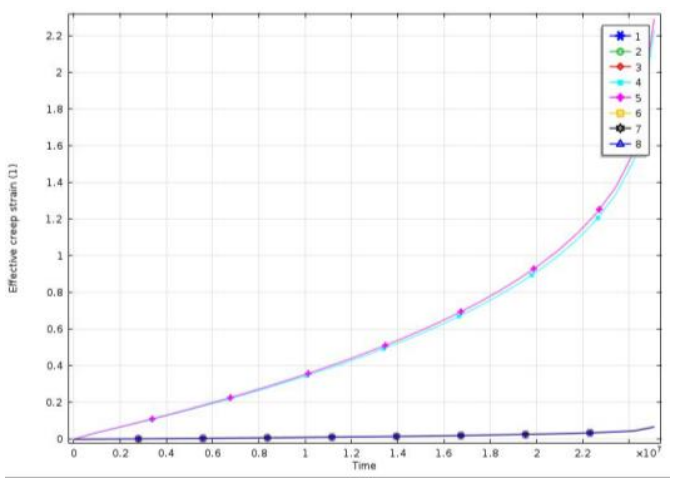

Figure 5. Creep strain distribution with the extension of time.

Referred to the stress concentration factor definition method under room temperature, the stress concentration factor under high temperature is defined as:

$$
K_{t} \leq \frac{\sigma^{F E}}{\sigma_{n}}
$$


Here, $\sigma^{F E}$ is the simulated stress, $\sigma_{n}$ is nominal stress. In the paper, the nominal stress is far away from the crack area, which is not affected by crack. As the creep is time-dependent, the nominal stress is also time-dependent.

Also taken elliptical crack with $a: b=1: 4$ for example, Fig . 6 is the distribution of the stress concentration factor, with the extension of the creep time. As shown in Fig .6, in the creep late stage, an obvious creep stress fluctuation was appeared.

Fig .7 is the creep strain rate distribution with the extension of time. As shown in Fig .7, obvious creep strain rate increase in the late creep, and the time of this increase is just consistent with the creep stress fluctuation. Thus, with the development of the time, in late creep, creep strain rate increase, leading to stress fluctuation in the latter part of the creep stress, forming a creep stress relaxation, which led to an increase in the latter part of the creep strain.

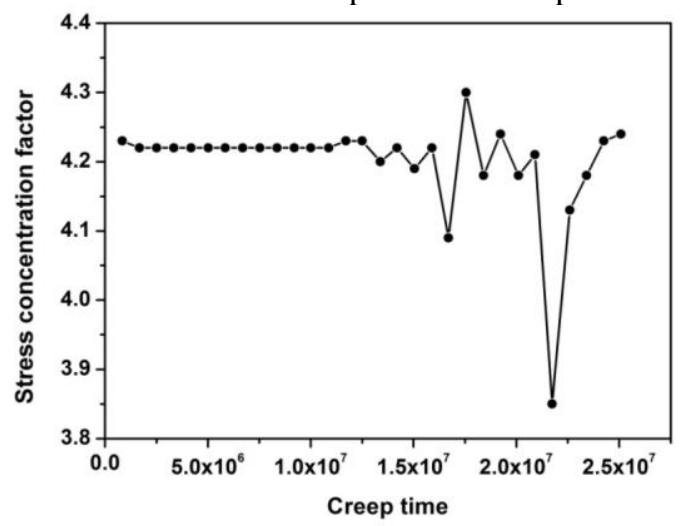

Figure 6. The distribution of the stress concentration factor with the extension of the creep time.

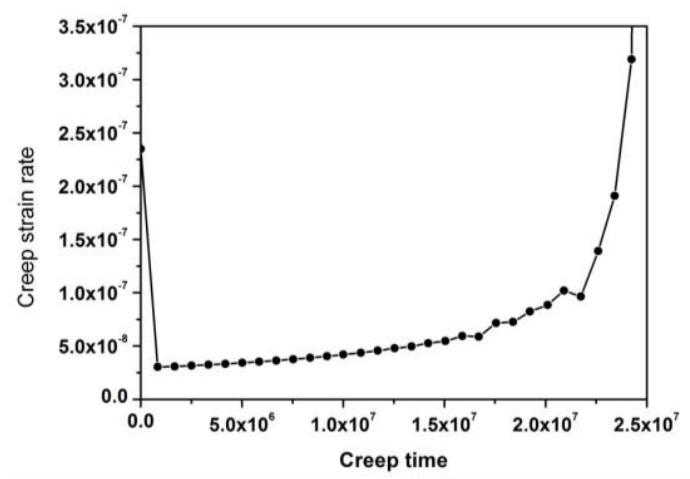

Figure 7. The creep strain rate distribution with the extension of time.

In general, as discussed above, the crack creep behavior under high temperature were given as follows:

- The stress concentration is very obvious in the tip of crack. The maximum creep stress values is always in the tip of crack long axis, which is 2.7 times the average stress values.

- With the extension of the creep time, the creep stress gradually decreases to a steady value, but in late creep, creep strain rate increases, leading to fluctuations in the latter part of the creep stress, forming a creep stress relaxation, which led to an increase in the latter part of the creep strain.

\section{CRACK INTERFERENCE EFFECTIVE}

\section{A. Numerical Simulated Model}

In order to research crack interference effective, in the paper, two ellipse cracks with the same size were selected for example. The interaction relationship was studied between these two ellipse cracks. Fig .8 is the distribution of two identical interference crack size. As shown in Fig .8, $\mathrm{C} 1$ is the benchmark crack, its size and location fixed, and $\mathrm{C} 2$ is interference crack. Due to interference effects between the two identical crack is the most obvious, $\mathrm{C} 1$, $\mathrm{C} 2$ were selected with the same crack size. In order to study the influence of crack spacing, the position of $\mathrm{C} 2$ was varied on different models.

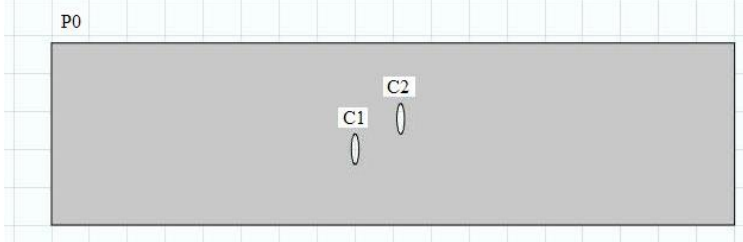

Figure 8. The distribution of two identical interference crack size

According to the principles of crack merger in GB/T19624-2004(Safety assessment for in-service pressure vessels containing defects), the arrangements of the two ellipse cracks were listed in Table I. S0 is the critical interference spacing between two cracks.

TABLE I. THE ARRANGEMENTS OF THE TWO ELLIPSE CRACKS

\begin{tabular}{|c|c|c|c|c|c|c|c|c|}
\hline & S0 & S1 & S2 & S3 & S4 & S5 & S6 & S7 \\
\hline Arrangements & 0 & 0 & 0 & 0 & 0 & 0 & 0 & 0 \\
\hline Spacing & $\backslash$ & $\frac{1}{4} s_{0}$ & $\frac{1}{2} s_{0}$ & $s_{0}$ & $2 s_{0}$ & $3 s_{0}$ & $4 s_{0}$ & $5 s_{0}$ \\
\hline
\end{tabular}

B. The Analysis of Crack Interference Effective

Take S1 for example. The creep stress of C1 is slightly larger the $\mathrm{C} 2$. The variation of stress and strain at the same position of $\mathrm{C} 1$ and $\mathrm{C} 2$ are consistent.

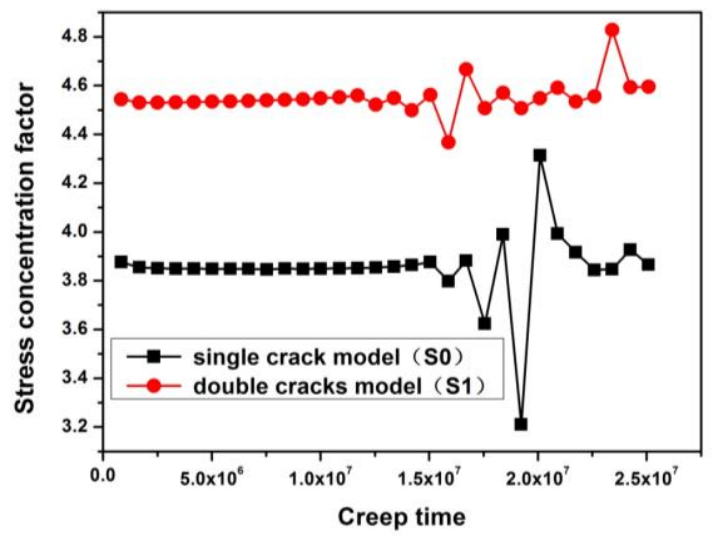

Figure 9. The stress concentration factor comparisons of $\mathrm{C} 1$ in single crack model and double cracks model. 


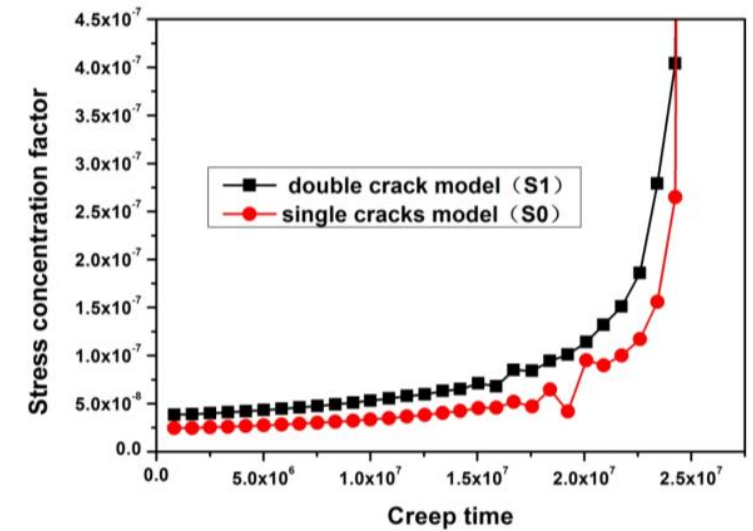

Figure 10. The strain rate comparisons of $\mathrm{C} 1$ in single crack model and double cracks model.

In order to analysis the crack interference effective, firstly, the creep behavior of $\mathrm{C} 1$ was compared between single crack model and double cracks model. Take S0 and S1 for example. Fig .9 is the stress concentration factor comparisons of $\mathrm{C} 1$ in single crack model and double cracks model. Fig .10 is the strain rate comparisons of $\mathrm{C} 1$ in single crack model and double cracks model. As shown in Fig .9and Fig .10, the stress concentration factor of C1 in double cracks model increased significantly than single crack model, the increase is around $20 \%$. Thus, under this interference space, the interference effective is very obvious, and the two cracks must be merged in safety assessment.

Fig .11 is the stress concentration factor with different interference effective spacing. As shown in Fig .11, with the interference effective spacing increases, the stress concentration factor of $\mathrm{C} 1$ decreases, and gradually decreases to a steady value. At the same time, the creep stress fluctuation in late creep stage is smaller than single crack model, because of the mutual restraint of the interference effective.

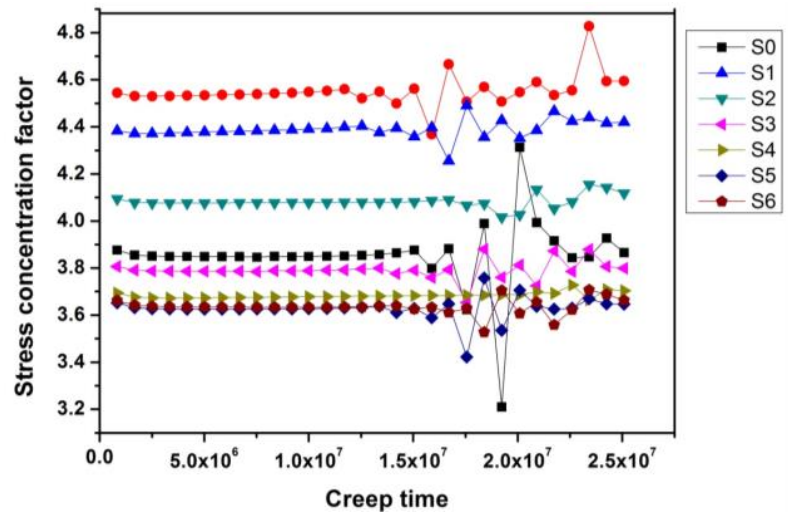

Figure 11. The stress concentration factor with different interference effective spacing.

Fig .12 is the stress concentration factor with different interference effective spacing at the same time $(t=25084800 s)$. As shown in Fig .12, the result of the interference effective is consistent with the standard. But, the interference effects are still evident, when the distance interference is 2 times the critical interference spacing. Thus, coefficient compensation must be given in safety assessment at high temperatures. The compensation range is 2 times the critical interference spacing.

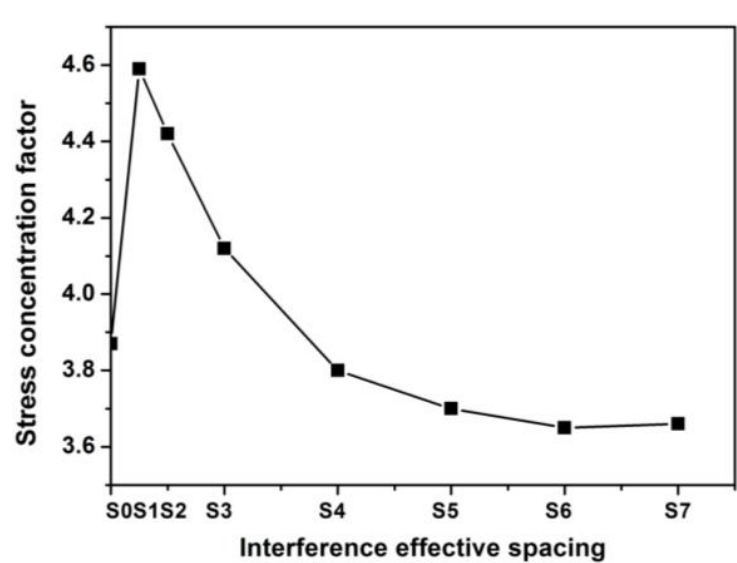

Figure 12. The stress concentration factor with different interference effective spacing at the same time $(\mathrm{t}=25084800 \mathrm{~s})$.

\section{CONCLUSION}

In general, as discussed above, the crack creep behavior and crack interference effective under high temperature can be given as follows:

- The stress concentration is very obvious in the tip of crack. The maximum creep stress values is always in the tip of crack long axis.

- With the extension of the creep time, the creep stress gradually decreases to a steady value, but in late creep, creep strain rate increases, leading to fluctuations in the latter part of the creep stress, forming a creep stress relaxation, which led to an increase in the latter part of the creep strain.

- The stress concentration factor of $\mathrm{C} 1$ in double cracks model increased significantly than single crack model. The interference effects are still evident, when the distance interference is 2 times the critical interference spacing. Thus, coefficient compensation must be given in safety assessment at high temperatures. The compensation range is 2 times the critical interference spacing.

\section{ACKNOWLEDGMENT}

This project is supported by the Major Project of Zhejiang Bureau of Quality and Technical Supervision(NO. 20110106 ). Correspondence concerning this article should be addressed to Ping Tang (tangpingjob@163.com).

\section{REFERENCES}

[1] R.K.Al-Rub, M.K. Darabi, "A thermodynamic framework for constitutive modeling of time and rate-dependent materials. Part I: theory". International Journal of Plasticity, vol. 34, Jul. 2012, pp. 61-92, doi: 10.1016/j.ijplas.2012.01.002.

[2] A. Zolochevsky, A. Martynenko , A. Kühhorn, "Structural benchmark creep and creep damage testing for finite element analysis with material tension-compression asymmetry and symmetry". Computers and Structures, vol. 100-101, Mar. 2012, pp. 27-38, doi:10.1016/j.compstruc.2012.02.021.

[3] L. Esposito, N. Bonora, "A primary creep model for Class M materials". Materials Science and Engineering A, vol. 528, Mar. 2011, pp.5496-5501, doi:10.1016/j.msea.2011.03.069.

[4] N. Aleš, K. Ladislav, U. Boris, "Uni-axial and multi-axial creep behavior of P91-type steel under constant load". Engineering Failure Analysis, vol. 18, Mar. 2011, pp. 61-67. doi:10.1016/j.engfailanal.2010.08.005.

[5] M. Basirat, T. Shrestha, G.P. Potirniche, "A study of the creep behavior of modified $9 \mathrm{Cr}-1 \mathrm{Mo}$ steel using continuum-damage 
modeling". International Journal of Plasticity, vol. 37, Jul. 2012, pp. 95-107, doi.org/10.1016/j.ijplas.2012.04.004.

[6] G.D. Zhang, Y.F. Zhao, F. Xue, "Creep-fatigue interaction damage model and its application in modified 9Cr-1Mo steel", Nuclear Engineering and Design , vol. 241, 2011, pp. 4856-4861. doi:10.1016/j.nucengdes.2011.08.076.

[7] T.H. Hyde, M. Saber, W. Sun, "Creep crack growth data and prediction for a P91 weld at $650^{\circ} \mathrm{C}$ ", International Journal of Pressure Vessels and Piping, vol. 87, 2010, pp.721-729, doi:10.1016/j.ijpvp.2010.09.002

[8] T.H. Hyde, M. Saber, W. Sun, "Testing and modelling of creep crack growth in compact tension specimens from a P91 weld at $650^{\circ} \mathrm{C}$ ", Engineering Fracture Mechanics, vol. 77, Apr. 2010, pp. 2946-2957, doi:10.1016/j.engfracmech.2010.03.043.
[9] S. Maleki, Y. Zhang, K. Nikbin, "Prediction of creep crack growth properties of P91 parent and welded", Engineering Fracture Mechanics, vol. 77, 2010, pp. 3035-3042, doi:10.1016/j.engfracmech.2010.04.022.

[10] G.Z. Wang, B.K. Li, F.Z. Xuan, "Numerical investigation on the creep crack-tip constraint induced by loading configuration of specimens", Engineering Fracture Mechanics, vol. 79, Nov. 2012, pp. 353-362, doi:10.1016/j.engfracmech.2011.11.014.

[11] F.J. Liu, P. Tang, S. Kong, "Investigations on creep behavior of p91-type steel using combined creep damage model", 2013 ASME Pressure Vessels and Piping Division Conference, Jul. 2013, pp.1418, Paris, France. 